\title{
FEMORAL ROLL BACK IN TOTAL KNEE ARTHROPLASTY: COMPARISON BETWEEN PROSTHESES THAT PRESERVE AND SACRIFICE THE POSTERIOR CRUCIATE LIGAMENT
}

Lúcio Honório de Carvalho Júnior ${ }^{1}$, Luiz Fernando Machado Soares², Matheus Braga Jacques Gonçalves², Leonardo Lanziotti Costa ${ }^{3}$, Lincoln Paiva Costa ${ }^{3}$, Rodrigo Rosa Lessa ${ }^{3}$, Marcelo Lobo Pereira ${ }^{3}$

\section{ABSTRACT}

Objective: To compare the rollback of the contact point between the femoral component and the tibial polyethylene as the knee is flexed, in two types of total knee arthroplasty: one that sacrifices and the other that preserves the posterior cruciate ligament (PCL). Methods: Under fluoroscopy, 36 knees from 32 patients who underwent total knee arthroplasty were evaluated. Using lateral images, the contact points between the femur and the tibial polyethylene with the knee in complete extension and at $90^{\circ}$ of flexion were measured, thereby measuring the percentage rollback of the femur in arthroplasties in which the PCL was sacrificed and in those in which it was preserved. Results: The mean percentage rollback of the femur was $13.24 \%$ in the cases in which the PCL was sacrificed and $5.75 \%$ in the cases in which it was preserved. The difference between these measurements was statistically significant $(p=0.026615)$. Conclusion: In total knee arthroplasty, sacrificing the PCL increased the rollback of the contact point between the femur and tibia as the knee was flexed up to $90^{\circ}$.

Keywords - Arthroplasty, Replacement, Knee; Biomechanics; Range of Motion, Articular

\section{INTRODUCTION}

Total knee arthroplasty (TKA) is one of the most successful procedures in the history of orthopedic surgery $^{(1)}$. Its durability is based on the quality and resistance of the polyethylene and the way in which the femoral component transmits the load onto the polyethylene ${ }^{(2)}$. For this load to be distributed better, prostheses are designed such that they attempt to reproduce the backward rolling action (rollback) of the femur on the tibia as the knee is bent (a movement in which rotation is associated with anterior translation of the tibia in relation to the femur). Theoretically, the more posteriorly that the load from the femur is borne on the tibia (when the knee is flexed), the better the load distribution is and the greater the durability of the implant and the polyethylene will be $\mathrm{be}^{(2)}$.

The objective of this study was to compare the rollback of the contact point between the femoral component and the tibial polyethylene as the knee is flexed, in two types of total knee arthroplasty: one in which the posterior cruciate ligament (PCL) is sacrificed and the other in which it is preserved.

\section{METHODS}

Thirty-six knees from 32 patients who underwent TKA performed by the authors at Hospital Madre Teresa, in Belo Horizonte, were analyzed under radioscopy. In all the cases, the Nex Gen ${ }^{\circledR}$ prosthesis

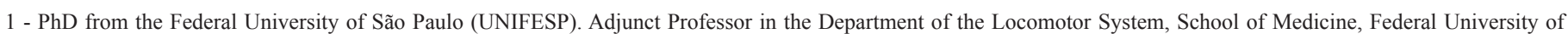
Minas Gerais; Member of the Knee Group at Hospital Madre Teresa, Belo Horizonte, Brazil.

2 - Member of the Knee Group at Hospital Madre Teresa, Belo Horizonte, Brazil.

3 - Physician undergoing Specialization training at Hospital Madre Teresa, Belo Horizonte, Brazil.

Work performed at Hospital Madre Teresa, Belo Horizonte.

Correspondence: Rua Olavo Carsalade Vilela, 264, Ipê da Serra - 34000-000 - Nova Lima, MG - E-mail: luciohcj@medicina.ufmg.br

Work received for publication: June 15, 2010; accepted for publication: August 23, 2010.

The authors declare that there was no conflict of interest in conducting this work 
manufactured by the company Zimmer ${ }^{\circledR}$ in Warsaw, Indiana, United States, was used. In 23 knees, the PCL was sacrificed and in 13, it was preserved. The choice between one type of prosthesis and the other was not random: it followed each surgeon's personal preference.

To analyze the images, the graphics processing software CorelDraw ${ }^{\circledR}$ Graphics Suite X4 was used. Through using a millimeter-grid tool, the images were orientated such that the base of the tibial component remained aligned with the horizontal. Its most anterior point was defined as the zero point and its posterior limit was defined as the point 100 . On images in extension, the point of least distance between the two components could be seen. This was named the point of peak load-bearing in extension (Pe) and thus, its position was defined in relation to the percentage of anteroposterior load-bearing. The same marking was made with the image in flexion at $90^{\circ}$, and the point of least distance between the components was defined as the point of peak load-bearing in flexion (Pf). The rollback rate (RR) was defined by calculating the difference between the percentage load-bearing in flexion and the percentage load-bearing in extension.

Figure 1 provides an example of the image obtained, although because not all the knees attained the same maximum flexion, all the measurements were made at full extension and at $90^{\circ}$ of flexion.

The difference between the measurements obtained for the two groups was calculated using Student's $t$ test for independent variables, with the aid of the Epi-Info computer software. Differences were considered to be significant when $p<0.05$.

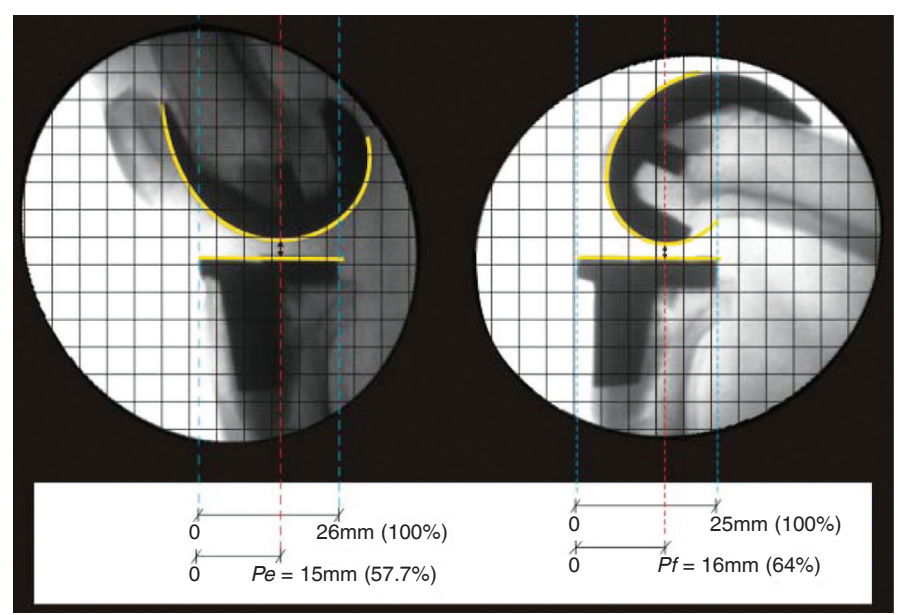

Figure 1 - Image showing determination of the point of peak loadbearing in extension and flexion, for calculating the rollback rate.
This study was approved by the institution's research ethics committee, and written consent was obtained from all the participants.

\section{RESULTS}

Among the 36 knees operated, 19 were from the right leg and 17 from the left leg; 30 operations were done on female patients and six on male patients. Among the arthroplasty procedures analyzed, the PCL was sacrificed in 23 cases and preserved in 13 cases. The minimum follow-up on the patients was 12 months.

The percentage rollback of the femur in relation to the tibial plateau in the preserved PCL group ranged from $-5.6 \%$ (i.e. anteriorization) to $18.2 \%$ (i.e. posteriorization), with a mean rollback of $5.7538 \%$ and standard deviation of 6.5448 .

In the sacrificed PCL group, the percentage rollback ranged from $-8.3 \%$ (anteriorization) to $27.2 \%$ (posteriorization), with a mean of $13.2435 \%$ and standard deviation of 10.520 .

The difference between the means was shown to be statistically significant, with $p=0.026615$.

\section{DISCUSSION}

The term "rollback" has been questioned by some authors regarding its appropriateness for correctly expressing what really happens in the human knee during flexion ${ }^{(3)}$. The medial tibial plateau barely moves, while the lateral plateau undergoes significant posterior translation. In the opposite direction, the latter plateau undergoes anterior translation during extension, in a coordinated action called a "screw home" movement ${ }^{(4)}$.

In most implants for knees undergoing total arthroplasty, the femoral condyles and tibial plateaus are equal, making flexion and translation simultaneously as shown in Figure 2. Shifting the contact point (from anterior to posterior) not only provides greater range of motion but also changes the load distribution, which may contribute towards increasing the durability of the arthroplasty ${ }^{(5)}$.

Despite this theoretical advantage, the benefit has not been documented. Some authors have even questioned whether this movement really exists ${ }^{(6)}$. Most et $\mathrm{al}^{(7)}$ questioned whether a PCL that had been altered 

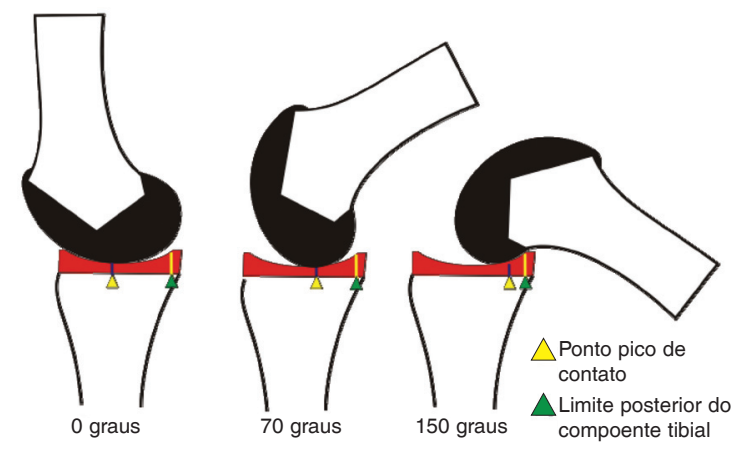

Figure 2 - Rollback of contact point between the femur and tibia in total knee arthroplasty, as the flexion increases.

through an arthrotic process would have the capacity to put this translation into effect. They argued that arthroplasty with sacrificing of the PCL would allow posterior translation to be made more effectively, which would contribute towards increasing the durability of the prosthesis through better load distribution. Their findings relating to posterior translation coincide with those of the present study, although the findings relating to durability are not confirmed by the literature, given that the durability is shown in the literature to be similar between the two types of $\operatorname{prosthesis}^{(3,7)}$.

Pinskerova et $\mathrm{al}^{(6)}$ argued that there are differences in the posterior translation of the contact point between the femoral and tibial components according to the angle of knee flexion. They observed that there was no translation before reaching $30^{\circ}$ and that translation really became important between $70^{\circ}$ and $120^{\circ}$. In the present study, $90^{\circ}$ was used as the measurement point, since this was the minimum angle common to all the knees, thus standardizing the evaluations.

Li et $\mathrm{al}^{(8)}$ questioned the analytical capacity of radioscopy to make an effective assessment of load distribution in the knee after arthroplasty, and argued that such analysis would only have some value if it was done under loading. Nonetheless, despite these considerations, they found results that were similar to those seen in the present study, regarding posterior translation of the load-bearing point of the femoral component.

Although there is a theoretical advantage relating to the possibility of greater durability of the implants when the PCL is sacrificed, the short follow-up of the present study did not allow conclusions to be reached in this regard. The fact that the cases were not chosen randomly means that any such conclusions would also not be reliable.

\section{CONCLUSION}

In total knee arthroplasty, sacrificing the PCL increased the rollback of the contact point between the femur and tibia as the knee was flexed up to $90^{\circ}$.

\section{REFERENCES}

1. Dennis DA, Komistek RD, Scuderi GR, Zingde S. Factors affecting flexion after total knee arthroplasty. Clin Orthop Relat Res. 2007;464:53-60.

2. Insall JN, Binazzi R, Soudry M, Mestriner LA. Total knee arthroplasty. Clin. Orthop Relat Res. 1985;(192):13-22.

3. Victor J, Banks S, Bellemans J. Kinematics of posterior cruciate ligamentretaining and -substituting total knee arthroplasty: a prospective randomised outcome study. J Bone Joint Surg Br. 2005;87(5):646-55

4. Li G, DeFrate LE, Park SE, Gill TJ, Rubash HE. In vivo articular cartilage contact kinematics of the knee: an investigation using dual-orthogonal fluoroscopy and magnetic resonance image-based computer models. Am J Sports Med. 2005;33(1):102-7.
5. Victor J, Bellemans J. Physiologic kinematics as a concept for better flexion in TKA. Clin Orthop Relat Res. 2006;452:53-8.

6. Pinskerova V, Johal P, Nakagawa S, Sosna A, Williams A, Gedroyc W, et al. Does the femur roll-back with flexion? J Bone Joint Surg Br. 2004; 86(6):925-31.

7. Most E, Zayontz S, Li G, Otterberg E, Sabbag K, Rubash HE. Femoral rollback after cruciate-retaining and stabilizing total knee arthroplasty. Clin Orthop Relat Res. 2003;(410):101-13.

8. Li G, Suggs J, Hanson G, Durbhakula S, Johnson T, Freiberg A. Three-dimensional tibiofemoral articular contact kinematics of a cruciate-retaining total knee arthroplasty. J Bone Joint Surg Am. 2006;88(2):395-402. 